\title{
Safety Filenote
}

National Cancer Institute

\section{Source}

National Cancer Institute. Safety Filenote. NCI Thesaurus. Code C115507.

A notation regarding the decisions, and/or clarification of any information pertaining to the safety report of a clinical trial. 